\title{
Nanomaterials for Energy Production and Storage
}

\author{
Vaishali R. Shinde, ${ }^{1}$ Won Bae Kim, ${ }^{2}$ Shrikrishna D. Sartale, ${ }^{3}$ and Tanaji P. Gujar ${ }^{4}$ \\ ${ }^{1}$ International Center for Young Scientists (ICYS), National Institute for Materials Science (NIMS), 1-2-1 Sengen, Ibaraki, \\ Tsukuba 305-0047, Japan \\ ${ }^{2}$ Advanced Materials Research Laboratory, School of Materials Science and Engineering, Gwangju Institute of Science and Technology, \\ (GIST), Gwangju 500-712, Republic of Korea \\ ${ }^{3}$ Department of Physics, University of Pune, Pune 411 007, India \\ ${ }^{4}$ Department of Physics and Institute for Functional Nanomaterials, University of Puerto Rico, San Juan, PR 00931-3343, USA
}

Correspondence should be addressed to Vaishali R. Shinde, shinde_vr2003@yahoo.com

Received 17 December 2012; Accepted 17 December 2012

Copyright (C) 2012 Vaishali R. Shinde et al. This is an open access article distributed under the Creative Commons Attribution License, which permits unrestricted use, distribution, and reproduction in any medium, provided the original work is properly cited.

With the increasing world population and burst of portable electronic devices, automobile and other industries, the consumption of energy in many forms has been intensively escalated. However, the world energy sources are being consumed fast and this has put the world in a ditch of energy crisis. On the other hand, the availability of sustainable energy is crucial for the economic growth and industrialization, thus, sufficient and inexpensive energy is the most important demand of today. So this is the time to conserve the nonrenewable energy sources as well as to find the alternative sources of energy production and storage. In response to the needs of modern society and emerging ecological concerns, the new, low-cost, and environmentally friendly energy conversion and storage systems should be investigated, and research and development of this field should be rapidly accelerated. Nanomaterials, with tailored characteristics at the nanometer scale, offer unique properties or combinations of properties and will play a vital role in the development of new energy technologies for energy production and storage.

In this special issue, we have selected out of received the relevant research articles and covered the broad field from worldwide scientists. In this issue we publish several research articles that are addressing these fields.

S. Sun et al. have introduced a carbon-free electrocatalyst based on $\mathrm{Pt} / \mathrm{Nb}-\mathrm{TiO}_{2}$ for proton exchange membrane fuel cells (PEMFC) applications, where a facile surfactant-free wet-chemical method was used to grow single-crystalline $\mathrm{Pt}$ nanoparticles (NP) on mesoporous $\mathrm{Nb}$-doped $\mathrm{TiO}_{2}$ hollow spheres in aqueous solution. The use of $\mathrm{Nb}-\mathrm{TiO}_{2}$ hollow spheres as substrate has been proved to provide a new type of cost-effective support with high corrosion resistance for Pt$\mathrm{NP}$. Interestingly, the growth of $\mathrm{Pt}-\mathrm{NP}$ on $\mathrm{Nb}-\mathrm{TiO}_{2}$ support could be controlled by manipulating the mass ratios between the $\mathrm{Pt}$ precursor and the $\mathrm{Nb}-\mathrm{TiO}_{2}$ support. The $\mathrm{Pt}-\mathrm{NP} / \mathrm{Nb}-$ $\mathrm{TiO}_{2}$ catalysts have been demonstrated to enhance activity and stability compared with the commercial E-TEK Pt/C catalyst.

I. K. Basily et al. have presented a role of nanotechnology for the production of clean fuel E-85 and petrochemical raw materials. The aim of this experiment was to obtain unsaturated hydrocarbons from petroleum residues with the help of different types of nanocatalyst and to optimize the pyrolysis parameters of the two-stage reactor. The studies on the effectiveness of catalysts such as $\mathrm{CaO}$ and gold nanocatalyst supported on $\mathrm{CaO}$ for the yield and product distribution have been carried out. In this work it has been concluded that the Au nanocatalyst with rods shape gives the maximum yield of ethylene (which can be converted easily to ethyl alcohols which is used as E-85 clean fuel) from petroleum residues.

Li-ion batteries are one of the efficient energy storage devices that have established a strong market position especially for portable electronic devices. In this context, T. Matsuda and Y. Moritomo have demonstrated two-electronreaction without structural phase transition in nanoporous cathode material. They have studied the charge/discharge properties, valence states, and structural properties of a nanoporous cathode material $\mathrm{Li}_{x} \mathrm{Mn}\left[\mathrm{Fe}(\mathrm{CN})_{6}\right]_{0.83} \cdot 3.5 \mathrm{H}_{2} \mathrm{O}$. Thin film of $\mathrm{Li}_{x} \mathrm{Mn}\left[\mathrm{Fe}(\mathrm{CN})_{6}\right]_{0.83} \cdot 3.5 \mathrm{H}_{2} \mathrm{O}$ was obtained by 
substitution of $\mathrm{Na}$ from $\mathrm{Na}_{1.32} \mathrm{Mn}\left[\mathrm{Fe}(\mathrm{CN})_{6}\right]_{0.83} \cdot 3.5 \mathrm{H}_{2} \mathrm{O}$ which was synthesized electrochemically on an indium tin oxide (ITO) transparent electrode. From the presented data it was clearly illustrated that the two-electron reaction without structural phase transition is responsible for the high charge capacity and the good cyclability observed in $\mathrm{Li}_{x} \mathrm{Mn}\left[\mathrm{Fe}(\mathrm{CN})_{6}\right]_{0.83} \cdot 3.5 \mathrm{H}_{2} \mathrm{O}$.

J. Y. Z. Chiou et al. have presented hydrogen production by reforming of ethanol over the PtRuMg/ZrO $\mathrm{Zr}_{2}$ catalyst. They have modified the $\mathrm{PtRu} / \mathrm{ZrO}_{2}$ catalyst with $\mathrm{Mg}$ and studied the oxidative steam reforming of ethanol (OSRE) and the steam reforming of ethanol (SRE) to realize the hydrogen production at a temperature lower than $300^{\circ} \mathrm{C}$ with higher ethanol conversion, hydrogen yield, and lower CO distribution. The results show that the OSRE reaction requires a higher temperature $\left(\sim 390^{\circ} \mathrm{C}\right)$ to achieve $100 \%$ ethanol conversion than the SRE reaction $\left(\sim 250^{\circ} \mathrm{C}\right)$. They have concluded that PtRuMg/ZrO${ }_{2}$ catalyst is suitable for SRE reaction considering the catalytic stability against the coke deposition.

Carbon aerogels, the nanostructured porous materials with reasonable high surface area and electric conductivity, are the potential candidate for electrochemical energy storage. A. Peña et al. have presented synthesis of carbon aerogels by catalytic chemical vapor deposition method (CCVD) using ferrocene as a source both of catalytic material $(\mathrm{Fe})$ and of carbon. Using the CCVD method they have obtained carbon aerogels with surface areas and pore volumes of $780 \mathrm{~m}^{2} / \mathrm{g}$ (SBET) and of $0.55 \mathrm{~cm}^{3} / \mathrm{g}(\mathrm{VBJH})$, respectively. According to their analysis, the large surface area is due to mesopores formed by the aggregation of carbon nanostructures. These porous Carbon aerogels present the promising features for applications in the physisorption of gases, for example, in the storage of molecular hydrogen for fuel cell applications.

Whilst storage of hydrogen is an important issue, the titanium decorated with organic compounds offers promising features for high-capacity hydrogen storage. F. Zuliani et al. have studied the adsorption of hydrogen molecules on a titanium atom supported by a benzene molecule using generalized gradient corrected Density Functional Theory (DFT) and elucidated the catalytic role of the Ti atom in the dissociation of the $\mathrm{H}_{2}$ molecule. The authors have analyzed the orbital interactions responsible for the $\mathrm{H}_{2}$ binding to Ti and for the dissociation of one $\mathrm{H}_{2}$ molecule. Their results reveal that up to four $\mathrm{H}_{2}$ molecules can coordinate to the metal ion center, with adsorption patterns similar to those observed in Ti-SWNTs and no more than one molecule dissociating in the process. With the detail studies and observation they have proposed $\mathrm{Ti}$ on carbon supports as a new and efficient material for hydrogen storage.

Vaishali R. Shinde Won Bae Kim Shrikrishna D. Sartale Tanaji P. Gujar 

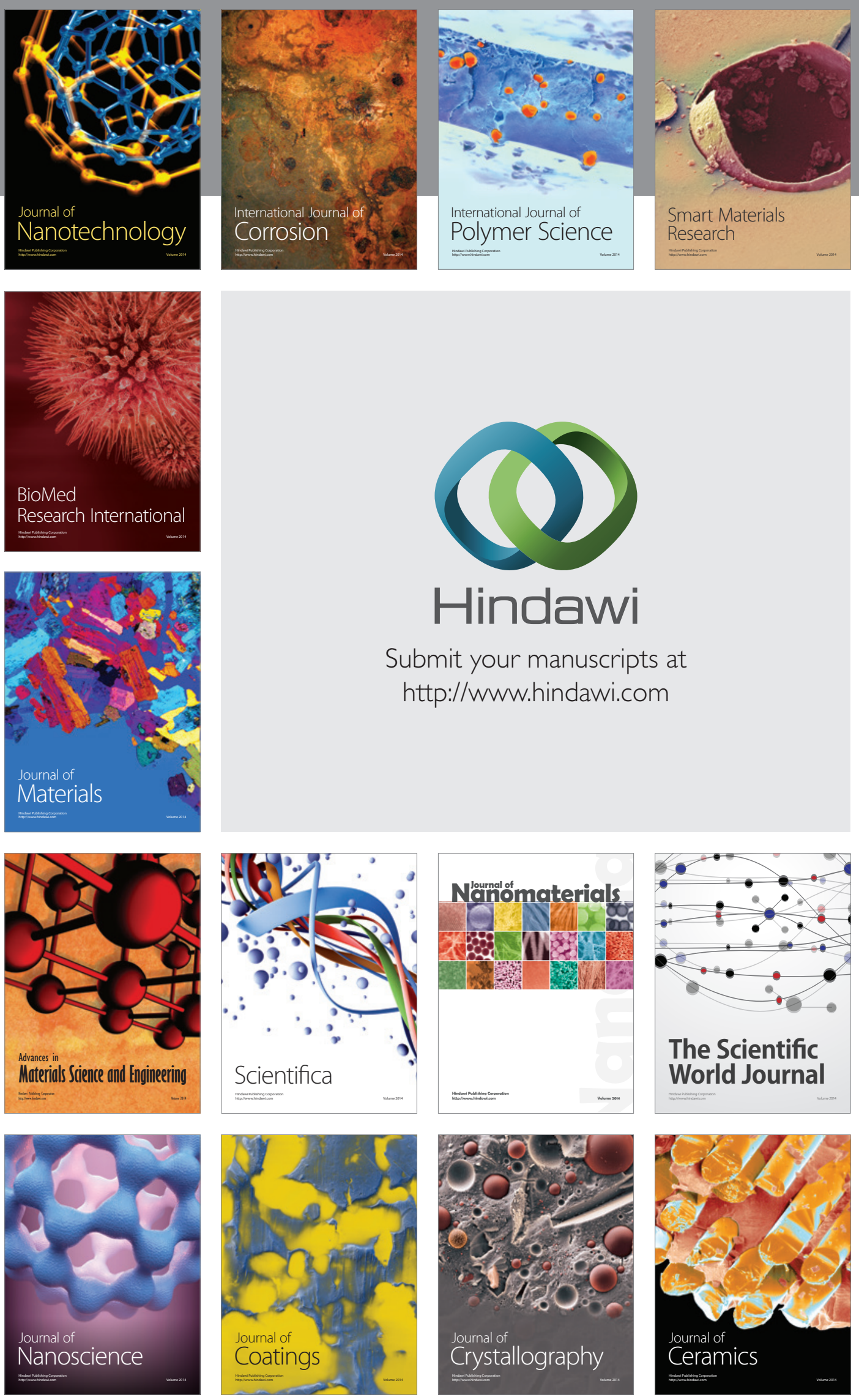

The Scientific World Journal

Submit your manuscripts at

http://www.hindawi.com

\section{World Journal}

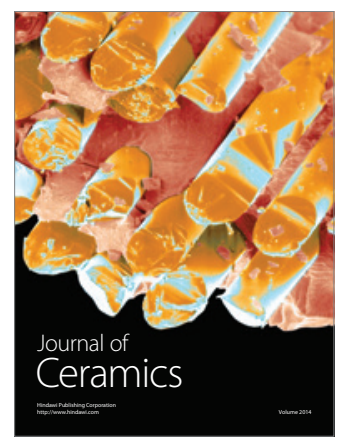

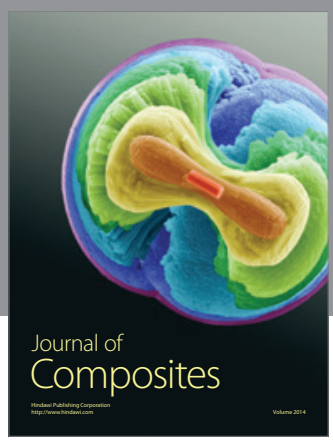
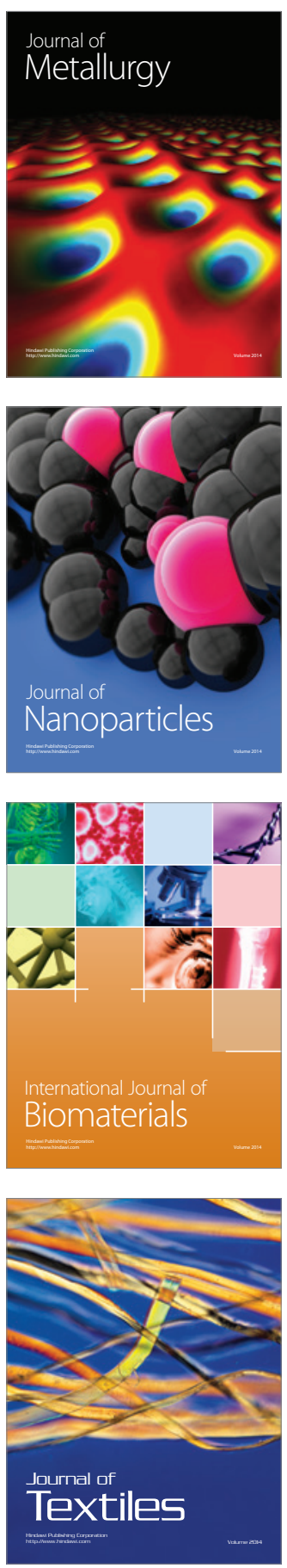